\title{
Penggunaan Peralatan Eksperimen Karakteristik Aliran Laminer Melewati Berbagai Bentuk dan Model Interaksi Benda
}

\author{
Hafrison Salamba $^{1 *}$ dan Edi Iskandar ${ }^{2}$ \\ ${ }^{1,2}$ PLP Laboratorium Mekanika Fluida, Departemen Teknik Mesin, Universitas Hasanuddin, Makassar 90245, Indonesia \\ *hafrisonsalamba@gmail.com
}

\begin{abstract}
The Laminar Flow Visualization and Analysis Unit (LFA) experimental equipment is equipment that was rezcently held in 2019 at the Fluid Mechanics Laboratory of the Mechanical Engineering Department of Hasanuddin University. For this reason, procedures for using the equipment must be prepared in the experimental fluid flow characteristics across various shapes and object interaction models. The characteristics of the use of LFA equipment become a reference for practicum and research for students and lecturers. The experimental method is to flow the fluid through 3 object shapes and 8 interaction object models (test objects) at 2 velocity levels, namely $0.44 \mathrm{~m} / \mathrm{s}$ and $0.52 \mathrm{~m} / \mathrm{s}$. Then record the visualization of the flow formed at each level of velocity and the test object. The results of the visualization show that if the shape of the objects is different, the growth pattern of the boundary layer, flow separation and flow vortex is different. Likewise, for each interaction between two or more objects, the same or different, it produces a different flow.
\end{abstract}

Keywords: Various forms and models of object interactio; laminar flow; flow visualization

\begin{abstract}
Abstrak: Eksperimen Laminar Flow Visualization and Analysis Unit (LFA) adalah peralatan yang baru diadakan pada tahun 2019 di Laboratorium Mekanika Fluida Departemen Teknik Mesin Universitas Hasanuddin. Untuk itu, harus dipersiapkan tatacara penggunaan peralatan dalam eksperimen karakteristik aliran fluida melintasi berbagai bentuk benda dan model interaksi benda. Karakteristik penggunaan peralatan LFA, menjadi acuan untuk praktikum dan penelitian mahasiswa serta dosen. Metode eksperimen adalah dengan mengalirkan fluida melewati 3 bentuk benda dan 8 interaksi model benda (benda uji) pada 2 tingkat kecepatan yaitu $0,44 \mathrm{~m} / \mathrm{s}$ dan $\quad 0,52 \mathrm{~m} / \mathrm{s}$. Selanjutnya merekam visualisasi aliran yang terbentuk pada masing-masing tingkat kecepatan dan benda uji tersebut. Hasil visualisasi menunjukkan bahwa bila bentuk benda berbeda, maka pola pertumbuhan lapisan batas, pemisahan aliran dan vortex aliran yang terbentuk berbeda. Demikian pula, untuk masing-masing interaksi antara dua benda atau lebih yang sama maupun berbeda, maka menghasilkan aliran yang berbeda.
\end{abstract}

Kata kunci : Berbagai bentuk dan model interaksi benda; aliran laminar; visualisasi aliran

\section{PENDAHULUAN}

Laboratorium Mekanika Fluida Departemen Teknik Mesin Universitas Hasanuddin, pada tahun 2019 mengadakan alat baru, berupa peralatan eksperimen Laminar Flow Visualization and Analysis Unit (LFA). Sehubungan dengan hal tersebut, maka harus dipersiapkan tatacara penggunaan peralatan tersebut untuk praktikum dan penelitian mahasiswa dan dosen. Berikut ini, dikemukakan beberapa hal yang berkaitan dengan pengembangan aliran fluida melewati suatu benda, khususnya penggunaan beberapa benda berbentuk pada berbagai rekayasa industri dan sistem transportasi.

Aliran fluida merupakan salah satu fenomena yang dapat ditemui dalam kehidupan sehari-hari. Melihat cakupan yang sangat luas dari fenomena aliran fluida, potensi untuk diadakannya penelitian terhadap fenomena aliran fluida juga sangat besar. Banyak sekali peneliti yang melakukan berbagai macam penelitian tentang fenomena aliran fluida. Hingga saat ini, permasalahan yang muncul pada penelitian tentang aliran fluida mulai kompleks. Oleh karena itu, didukung dengan perkembangan teknologi yang semakin maju, para peneliti mulai mengembangkan dan membuat metode-metode baru dalam pemecahan masalah aliran fluida yang kompleks.

Pesatnya perkembangan ilmu pengetahuan dan teknologi menginspirasi manusia untuk menciptakan sesuatu hal yang berguna bagi kehidupan manusia itu sendiri. Demikian halnya dengan aplikasi di bidang mekanika fluida, baik dalam dunia industri maupun dalam kehidupan sehari-hari. 
Salah satu bagian yang dipelajari dalam ilmu mekanika fluida yaitu aliran eksternal yang melintasi suatu body.

Dalam hal ini dapat dijumpai pada alat penukar panas (heat exchanger) yaitu pada shell and tube, cerobong, maupun penyangga anjungan lepas pantai. Pengetahuan mengenai karateristik aliran fluida yang mengalir melingkupi sebuah body inilah yang dapat digunakan untuk memperoleh suatu nilai yang optimum serta kontruksi bangunan yang ideal dan minim kesalahan. Pada silinder yang dilintasi suatu aliran fluida cenderung mempunyai streamline yang simetris sehingga hanya mempunyai gaya hambat (drag force), hal ini disebabkan adanya adverse pressure yang berakibat timbulnya net pressure dimana net pressure tersebut terjadi karena terbentuknya flow separates. Akibat adanya gaya hambat (drag force) tersebut kualitas dari sistem aliran yang melintasi silinder sirkular banyak berkurang.

Salah satu upaya untuk mengurangi gaya hambat (drag) adalah penelitian yang dilakukan oleh Aiba dan Watanabe [1] yaitu menggunakan model silinder teriris. Tipe yang digunakan dalam percobaan adalah tipe I dan tipe-D. Penelitian secara eksperimental yang dilakukan Schubauer [2], pada silinder elip dengan axis ratio $(\mathrm{AR}=1 / 3)$ menunjukkan bahwa transisi aliran laminar menjadi turbulen hingga terseparasi masif yang secara kuantitatif ditunjukkan oleh distribusi koefisien tekanan (Cp), sangat dipengaruhi oleh kecepatan free-stream (bilangan Reynolds), dimana semakin besar harga kecepatan aliran maka separasi masif semakin tertunda ke belakang. Penelitian oleh Faruqee, dkk [3] menggunakan perangkat lunak CFD solver Fluent, dengan melakukan simulasi numerik aliran melintasi silinder ellips dengan variasi axis ratio $(\mathrm{AR})=0,3$ hingga 1 , pada bilangan Reynolds rendah $(\operatorname{Re}=40)$. Simulasi numerik tersebut dilakukan karena kajian eksperimental tidak dapat melakukan pengukuran pada bilangan Reynolds yang sangat rendah. Penelitian tersebut mengambil berbagai hasil kuantitatif seperti distribusi koefisien tekanan, profil kecepatan pada maximum thickness-nya, serta mengintegrasikan harga $\mathrm{Cp}$ untuk mendapatkan koefisien pressure drag, serta skin friction drag, dengan mengintegrasikan distribusi wall shear stress.

Bungaran Nadeak [4] dalam penelitiannya yaitu pengaruh dinding datar dari elips dan silinder yang disusun tandem dengan berbagai jarak gap menunjukkan bahwa, mula-mula untuk semua jarak G/D nilai $\mathrm{Cp}$ pada posisi $\mathrm{x} / \mathrm{D}<0.6$ adalah sama karena aliran fluida belum terganggu, selanjutnya terlihat perubahan nilai $\mathrm{Cp}$ pada setiap jarak G/D. Favorable pressure gradient mengidentifikasikan akselerasi maksimum disaat momentum fluida akan memasuki sisi celah silinder-1, dan pada G/D 0.067 terjadi favorable pressure gradient yang menonjol dibandingkan dengan G/D yang lain. Penurunan nilai $\mathrm{Cp}$ pada $\mathrm{x} / \mathrm{D}=0$ untuk $\mathrm{G} / \mathrm{D}=0.067$ ditunjukkan dengan peningkatan kecepatan yang signifikan hingga pada $\mathrm{x} / \mathrm{D}=0$ ditandai dengan penurunan nilai $\mathrm{Cp}$. Fenomena ini mengidentifikasikan bahwa nilai $\mathrm{Cp}$ tepat dibawah silinder sirkular upstream pada sudut 270o juga mengalami pressure gradient. Interaksi aliran fluida pada dinding datar (flat wall) yang didekatkan dengan dua silinder elip tersusun tanden (L/D $=1.5$ ) dengan berbagai variasi gap secara umum nilai $\mathrm{Cp}$ yang terjadi pada plat datar cenderung menurun dan berharga negatif. Sebelum kecepatan freestream terganggu oleh silinder terlihat bahwa nilai $\mathrm{Cp}$ untuk semua jarak gap adalah sama yang terlihat dari nilai $\mathrm{Cp}$ pada $\mathrm{x} / \mathrm{D}=-1.0$ sampai $\mathrm{x} / \mathrm{D}=-0.8$, kemudian akibat adanya celah yang kecil antara silinder dengan dinding maka terjadi peningkatan kecepatan dan nilai $\mathrm{Cp}$ menurun, untuk $\mathrm{G} / \mathrm{D}=$ 0.067 niai $\mathrm{Cp}$ pada $\mathrm{x} / \mathrm{D}=0$ adalah sangat kecil. Hal in memperkuat informasi bahwa nilai $\mathrm{Cp}$ untuk Permukaan silinder elip tepat diatas $\mathrm{x} / \mathrm{D}=0$ adalah kecil.

Nilai $\mathrm{Cp}$ untuk $\mathrm{G} / \mathrm{D}=0.133,0.2,0.0267$ berturut-turut meningkat sampai $\mathrm{x} / \mathrm{D}=0.3$. Adanya lembah menunjukkan terjadinya akselerasi maksimum sesaat momentum fluida akan memasuki sisi celah silinder elips.

Unit Visualisasi dan Analisis Aliran Laminar (LFA) memungkinkan studi lengkap tentang masalah dua dimensi yang terkait dengan aliran laminar dengan cara visualisasi model aliran yang berbeda yang dapat divisualisasikan dengan bantuan sistem injeksi yang efisien. cairan berwarna. Unit LFA dirancang untuk menunjukkan aliran fluida dalam bidang dua dimensi. Kecepatan yang lambat 
dari fluida dan ruang kecil antara lembaran superior dan inferior akan memberikan nilai rendah sebagai hasil dari bilangan Reynolds.

Penelitian secara eksperimental dilakukan oleh Lajos [5] tentang reduksi gaya hambat pada bluff body yang memiliki adverse pressure gradient lemah, dengan melakukan modifikasi bentuk sisi depan bluff body tersebut. Modifikasi yang dilakukan menghasilkan separasi bubble pada kontur permukaan bluff body tersebut, dan mampu mereduksi gaya hambat hingga $50 \%$ apabila dibandingkan bentuk tanpa modifikasi.

Peneliti lain seperti Yaghoubi dan Mahmoodi [6], melakukan kajian eksperimental fenomena separating dan reattaching aliran turbulen pada benda berbentuk balok, dimana pengamatan tentang fenomena separasi bubble pada kontur plat datar (2-dimensi) dengan berbagai aspect ratio panjang terhadap tingginya $(\mathrm{L} / \mathrm{H})=4,5,6$, dan 9, pada bilangan Reynolds $(\mathrm{ReH})=3,6 \times 104$.

Penelitian yang dilakukan baik oleh Lajos [5] maupun Yaghoubi dan Mahmoodi [6], menunjukkan fenomena separating-reattching sepanjang kontur benda yang tidak memiliki kelengkungan (curvature). Kelengkungan kontur menyebabkan menguatnya adverse pressure gradient, kondisi ini akan mempengaruhi terbentuknya separasi bubble maupun separasi masif pada benda tersebut. Penelitian tersebut menjelaskan bahwa fenomena transisi aliran laminar hingga menjadi turbulen, dengan diawali dengan terbentuknya separasi bubble, diamati dengan perubahan profil kecepatan aliran, intensitas turbulensi, serta shape factor sepanjang kontur permukaan pelat datar.

Penelitian oleh Bao dan Dallman [7], mengkaji lebih detail berbagai aspek fisis terbentuknya separasi bubble yang melalui geometri berbentuk rounded backward- facing step, baik dari kajian eksperimental maupun pemodelan numerik. Penelitian tersebut dapat lebih menjelaskan evolusi lapis batas yang attach pada kontur permukaan yang bertransisi dari aliran laminar hingga menjadi turbulen, yang diantaranya dipengaruhi adanya separasi bubble.

Penelitian lainnya tentang pengendalian aliran pasif, selain malakukan modifikasi geometri seperti yang dilakukan oleh Aiba dan Watanabe [1] serta Igarashi dan Shiba [8], yaitu dengan menempatkan benda pengganggu (inlet disturbance body) yang diletakkan di depan silinder utama dengan posisi tandem. Penelitian tersebut telah dilakukan oleh Igarashi [8], Tsutsui dan Igarashi [9], serta Lee, SangJoon, dkk. [10], dimana kedua peneliti tersebut menggunakan silinder sirkular kecil sebagai silinder pengganggu. Prasad \& Williamson [11], menggunakan plat datar yang memiliki dimensi tertentu dengan posisi vertikal dan horisontal (normal terhadap arah aliran) yang diletakkan di depan silinder utama. Keser dan Unal [12], menggunakan blunt-based flat plate yang ditempatkan pada jarak tertentu terhadap silinder utama dengan posisi tandem.

Aliran viscous adalah aliran dimana viscositasnya tidak di abaikan dan berada di dalam boundary layer sedangkan non viscous adalah dimana viscositasnya di abaikan dan berada di luar buondary layer. Fluida yang tidak di pengaruhi oleh tegangan geser dimana viscositasnya di anggap tidak ada aliran tersebut juga dapat di sebut dengan aliran inviscid. Perbedaan dari dua aliran tersebut dapat di lihat pada gambar 1 berikut ini.

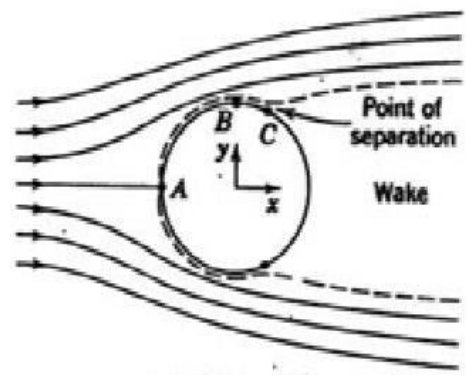

(a) Viscos flow

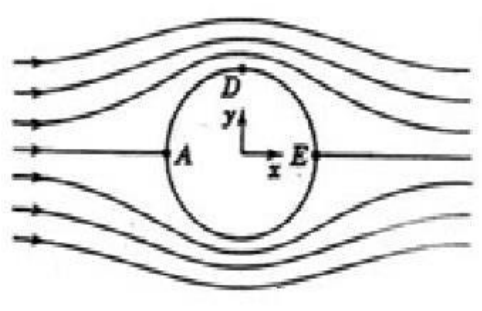

(b) inviscid flow

Gambar 1 Aliran Melintasi Silinder sirkular [13] 
Lapisan batas atau Boundary layer adalah lapisan tipis pada solid surface yang terbatas daerah sangat sempit dekat permukaan kontur dimana adanya gradien kecepatan sebagai pengaruh dari tegangan geser yang muncul akibat adanya viscositas.

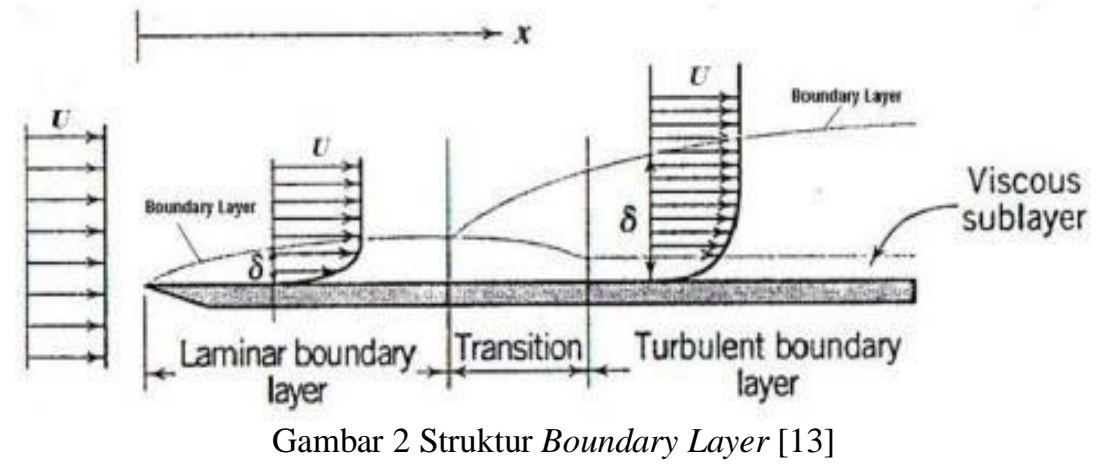

Perhatikan gambar 2 pada awalnya fluida mengalir dengan kecepatan yang sama, kemudian saat melewati pelat tipis kecepatan fluida mengalami perubahan. Perubahan ini dipengaruhi oleh adanya tegangan geser antara fluida dengan permukaan padat tersebut, hal ini menyebabkan lapisan batas (boundary layer). Akibat terjadinya tegangan geser yang terus menerus sepanjang benda membuat garis lapisan batas semakin tebal.

Semakin lama kecepatan di daerah boundary layer dan di luar boundary layer akan bergabung sehingga sangat sulit untuk mengukur tebal lapisan batas (boundary layer). Tebal lapisan batas pada awal ujung plat (leading edge) masih tipis, kemudian partikel-partikel bergerak secara berlapis-lapis dan lapisan batas yang terjadi merupakan laminar boundary layer. Selanjutnya fluida bergerak menjauhi ujung plat, lapisan batas semakin tebal dan aliran akan berubah mendekati turbulen. Semakin jauh dari ujung pelat, maka aliran fluida menjadi tidak stabil dan terjadi pergolakan antar partikel fluida, yang mengakibatkan aliran berubah menjadi lapisan batas turbulen.

\section{METODE PENELITIAN}

Penelitian ini, menggunakan metode eksprimen, yang bertujuan untuk mendapatkan karakteristik visualisasi aliran laminer melewati berbagai bentuk dan interaksi dua atau lebih benda, dengan menggunakan peralatan yang baru diadakan yaitu Laminar Flow Visualization and Analysis Unit (LFA). Pelaksanaan penelitian di Laboratorium Mekanika Fluida Departemen Teknik Mesin Fakultas Teknik Universitas Hasanuddin.

Bentuk benda uji yang menjadi objek utama penelitian, merupakan bentuk benda uji yang telah tersedia satu paket dengan pengadaan peralatan tersebut, dimana bentuknya seperti pada gambar 3 berikut ini: 
Circular models

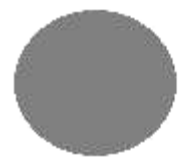

$80 \mathrm{~mm}$

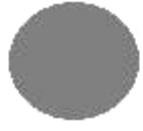

$60 \mathrm{~mm}$

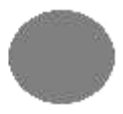

$40 \mathrm{~mm}$

Square models:

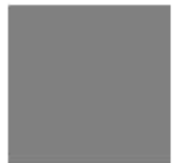

80mm

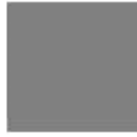

$60 \mathrm{~mm}$

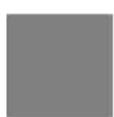

$40 \mathrm{~mm}$

Wing model

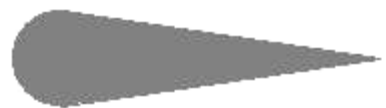

Gambar 3 Bentuk Benda Uji [14]

Feeding or emptying

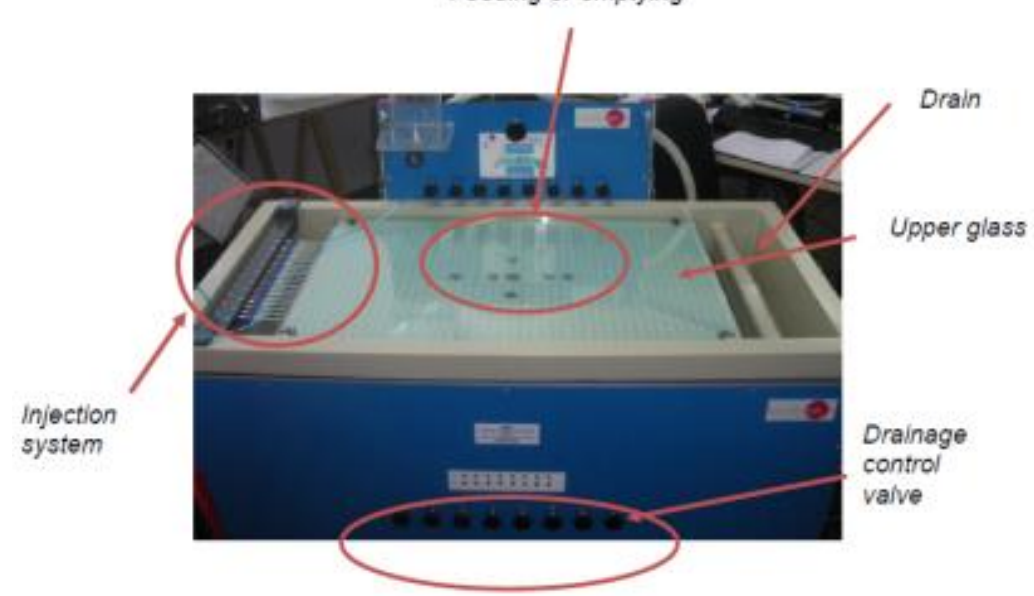

Gambar 4 Peralatan Laminar Flow Visualization and Analysis Unit (LFA) [14]

Pengambilan data visualisasi aliran pada masing-masing bentuk benda dan model interaksi benda tersebut dengan bentuk benda lainnya. Selanjutnya diberikan perlakuan dalam 2 tingkat kecepatan aliran air, yaitu $0,44 \mathrm{~m} / \mathrm{s}$ dan $0,52 \mathrm{~m} / \mathrm{s}$. Gambar 5 berikut ini menunjukkan model interaksi masingmasing benda.

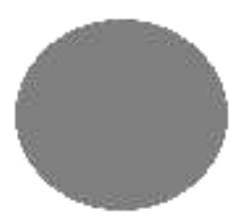

(b)

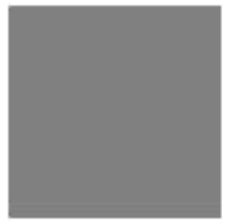

(c)

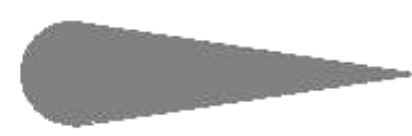

(d)

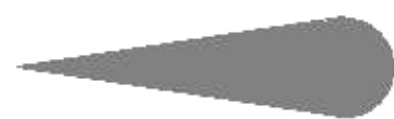



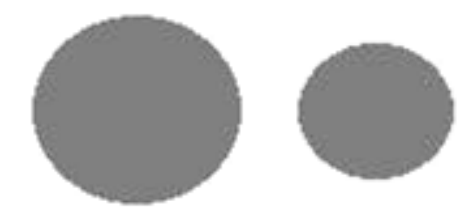

(e)

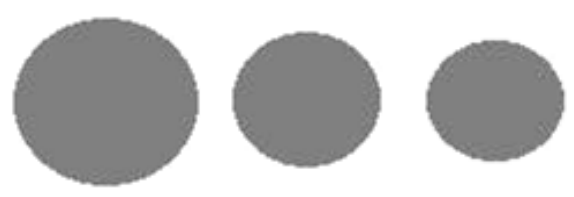

(g)

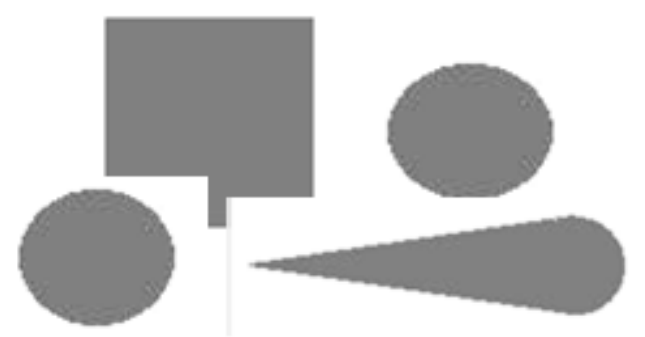

(j)
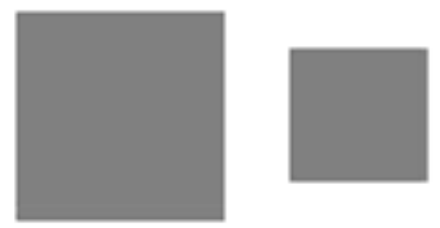

(f)
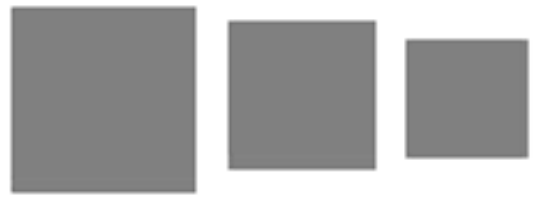

(h)
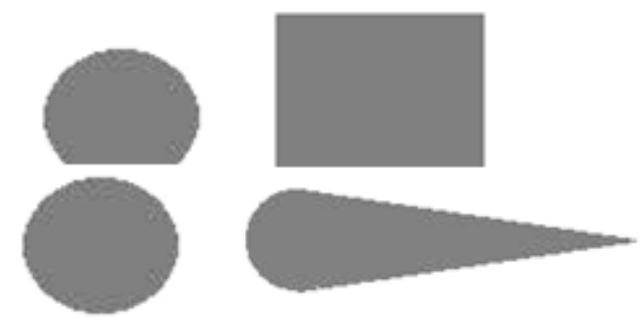

(1)

Gambar 5 Bentuk dan Model Interaksi Benda Uji (a) silinder bundar, (b) silinder persegi, (c) aerofoil, (d) aerofoil terbalik, (e) model interaksi silinder bundar, (f) model interaksi silinder persegi, (g) model interaksi 3 silinder bundar, (h) model interaksi 3 silinder persegi, (i) model interaksi silinder persegi dengan silinder bundar, (j) model interaksi silinder bundar dengan silinder persegi, (k) model interaksi silinder bundar dengan airfoil terbalik, dan (l) model interaksi silinder bundar dengan airfoil.

Untuk mengetahui apakah aliran laminar, maka ditentukan besarnya bilangan Reynolds (Re). Bilangan ini merupakan parameter yang di gunakan sebagai nilai patokan dalam menentukan aliran laminar dan turbulen dari fluida. Di dalam aplikasinya bilangan Reynolds dapat di tentukan dengan persamaan sebagai berikut [13]:

$$
\operatorname{Re}=\frac{\rho D V}{\mu}
$$

Variabel $\rho$ adalah densitas fluida $\left(\mathrm{kg} / \mathrm{m}^{3}\right)$, D adalah diameter atau panjang permukaan benda uji $(\mathrm{m}), \mathrm{V}$ adalah kecepatan aliran fluida $(\mathrm{m} / \mathrm{s}), \mu$ adalah viscositas dinamik fluida $(\mathrm{kg} / \mathrm{m} . \mathrm{s})$. Untuk jenis aliran pada aliran external atau aliran melewati benda, maka daerah bilangan Reynolds untuk masing-masing aliran adalah sebagai berikut [13]. Untuk $\operatorname{Re}=<10^{5}$ aliran laminar, untuk $\operatorname{Re}=10^{5}$ aliran transisi, dan untuk $\operatorname{Re}=>10^{5}$ aliran turbulen.

\section{HASIL DAN PEMBAHASAN}

Visualisasi aliran benda dan model interaksi benda pada gambar 6 di bawah ini, menunjukkan karakteristik aliran pada kecepatan air $0,44 \mathrm{~m} / \mathrm{s}$ dimana pemisahan aliran terjadi di sisi hulu, sehingga vorteks aliran di atas benda tersebut cukup besar. Selanjutnya pada model interaksi benda pemisahan 
aliran tetap terjadi pada benda di depan (1), namun lebih tipis pada benda yang di belakang (2). Hal ini disebabkan karena vorteks aliran teredam diantara benda (1) dengan benda (2). Untuk model interaksi 3 benda, pemisahan aliran kembali lebih besar pada benda (1) dan benda (2), namun teredam saat melewati benda (3), sehingga pemisahan aliran lebih kecil dibandingkan model interaksi 2 benda. Hal ini disebabkan karena vorteks aliran lebih teredam diantara benda (1) dengan benda (2) dan vorteks aliran yang terbentuk ini lebih tenang yang menyebabkan terjadi pemisahan aliran dapat ditunda di sisi hilir benda (3). Pemisahan aliran yang terjadi pada 8 model interaksi bentuk benda tersebut di bawah ini, mengikuti pola pemisahan aliran yang terjadi pada setiap model interaksi benda.

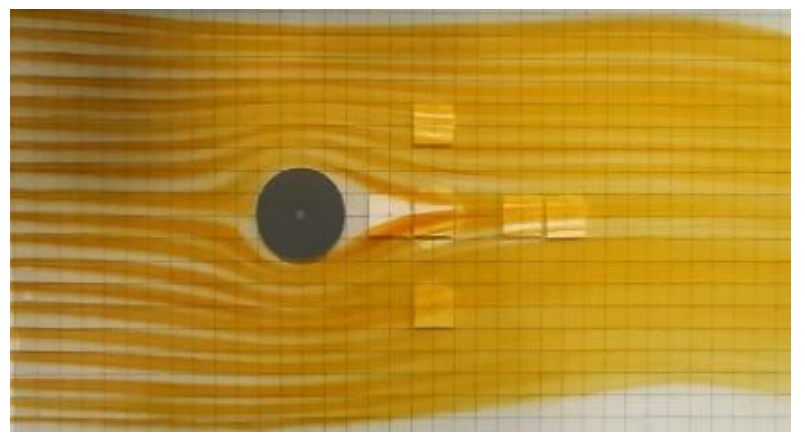

(a)

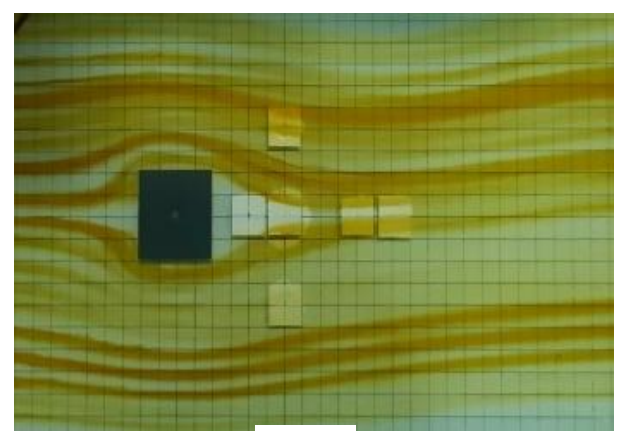

(b)

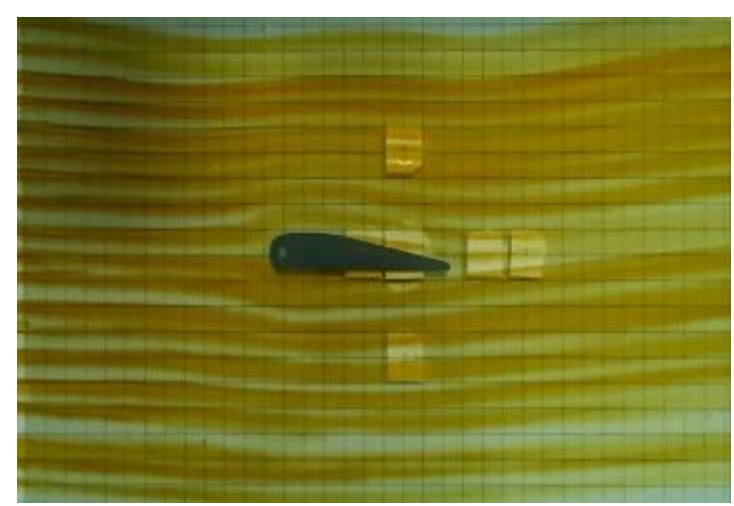

(c)

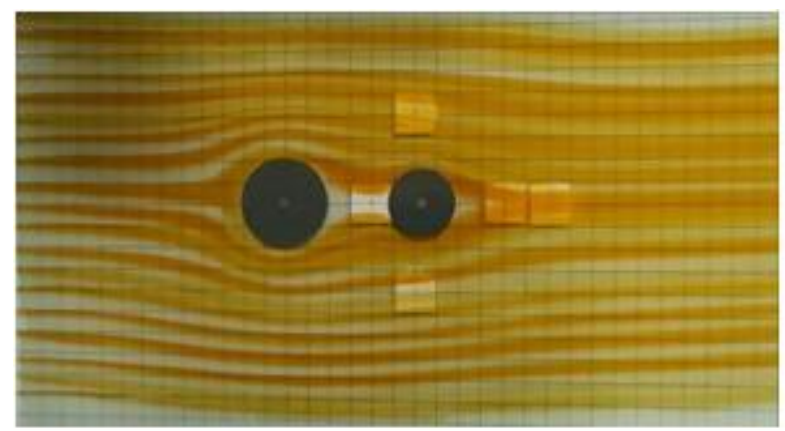

(e)

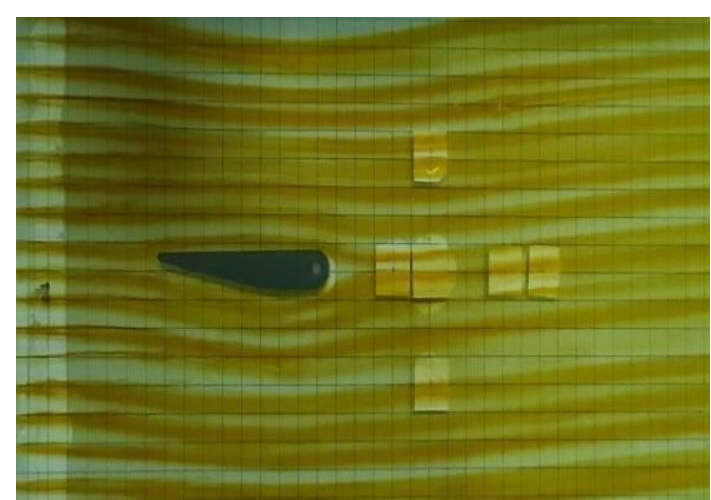

(d)

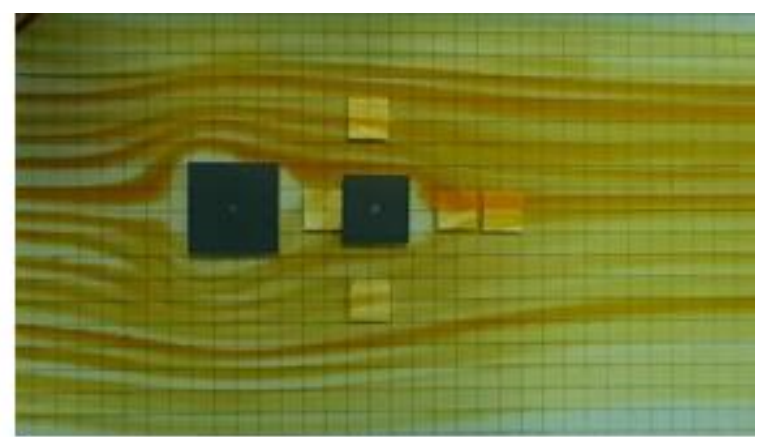

(f) 


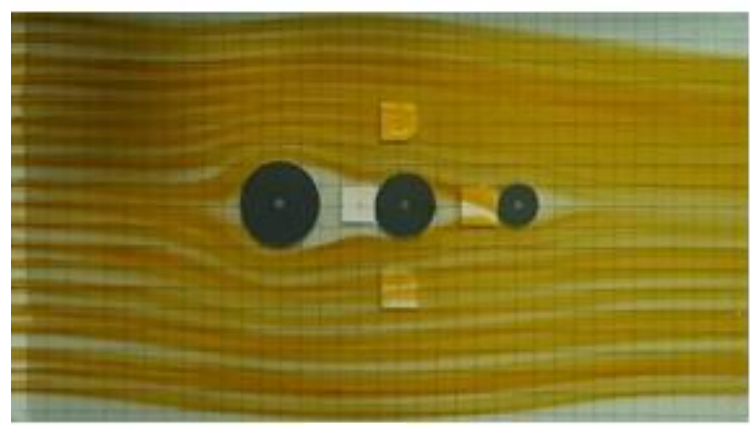

(g)

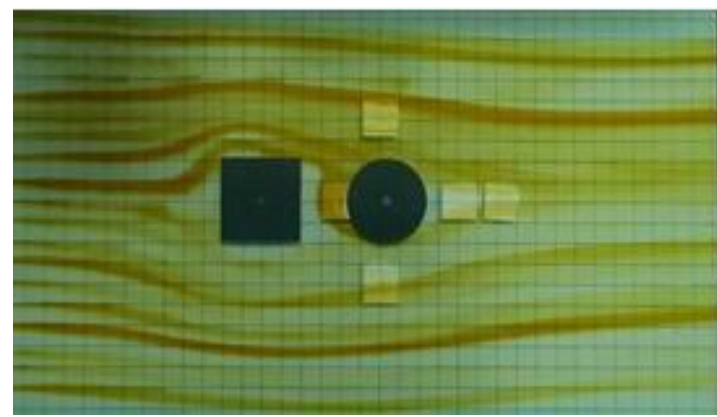

(i)

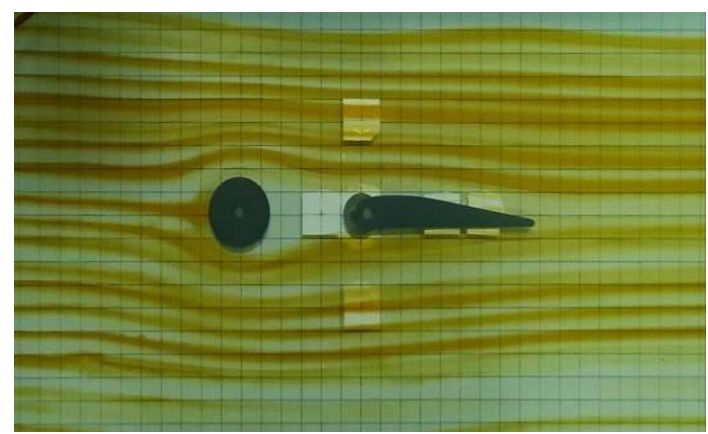

(k)

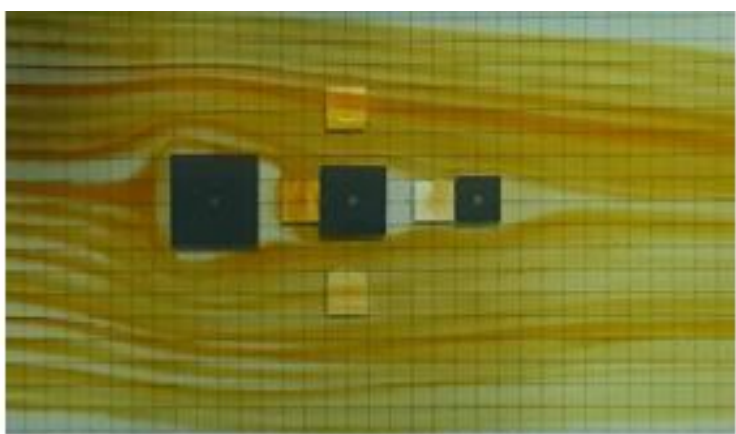

(h)

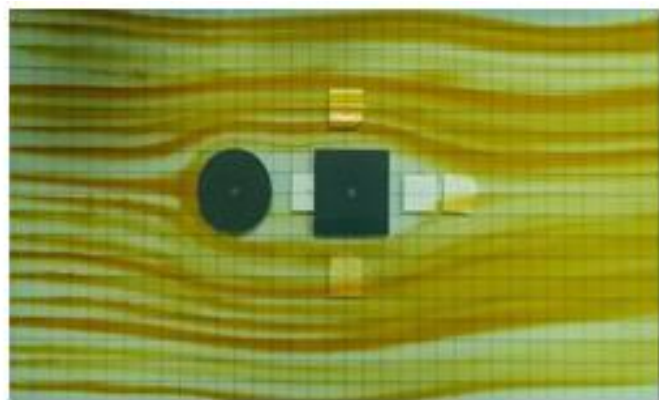

(j)

Gambar 6 visualisai benda uji pada kecepatan 0,44 m/s (a) silinder bundar, (b) silinder persegi, (c) aerofoil, (d) aerofoil terbalik, (e) model interaksi silinder bundar, (f) model interaksi silinder persegi, (g) model interaksi 3 silinder bundar, (h) model interaksi 3 silinder persegi, (i) model interaksi silinder persegi dengan silinder bundar,

(j) model interaksi silinder bundar dengan silinder persegi, (k) model interaksi silinder bundar dengan airfoil terbalik, dan (l) model interaksi silinder bundar dengan airfoil.

\section{KESIMPULAN}

Berdasarkan hasil eksperimen tersebut di atas, maka dapat disimpulkan bahwa, penggunaan peralatan Laminar Flow Visualization and Analysis Unit (LFA) untuk visualisasi aliran menunjukkan hasil yang sangat baik. Karakteristik aliran melewati benda menunjukkan, bahwa bila bentuk benda berbeda, maka pola pertumbuhan lapisan batas, pemisahan aliran dan vortex aliran yang terbentuk juga berbeda. Demikian pula, untuk masing-masing model interaksi antara dua benda atau lebih yang sama maupun berbeda, maka menghasilkan pola aliran yang berbeda. 


\section{UCAPAN TERIMA KASIH}

Kami menghaturkan terima kasih dan penghargaan, kepada Universitas Hasanuddin karena penelitian ini dibiayai melalui skema Penelitian Tenaga Kependidikan Fungsional Tahun Anggaran 2020, yang dikelola oleh Sekretaris Universitas Hasanuddin. Demikian pula, kepada Kepala dan Wakil Kepala Laboratorium Mekanika Fluida Fakultas Teknik Universitas Hasanuddin, yang memberikan izin dan membantu pelaksanaan penelitian ini.

\section{DAFTAR PUSTAKA}

[1] Aiba, S., and Watanabe, H., June 1997. "Flow Characteristics of a Bluff Body Cut from a Circular Cylinder", Journal of Fluids Engineering, Vol 119/453-457.

[2] Nadeak Bungaran, 2010. "Studi Eksperimental Perbandingan Aliran Melintasi Dua Silinder Elips dan Dua Silinder Sirkuler Tersusun Tandem Akibat Pengaruh Dinding Datar Pada Berbagai Jarak Gap". Laporan Tugas Akhir, Jurusan Teknik Mesin FT-UNIB, Bengkulu.

[3] Tsutsui, T., and Igarashi, T., 2002. "Drag Reduction of a Circular Cylinder in an Air-stream", Experimental Thermal and Fluid Science, 90, 527-541.

[4] Choi, J.H. \& Lee, S.J, 2000. "Ground Effect of Flow Arround an Elliptic Cylinder in a Turbulent Boundary Layer". Journal of Fluids and Structures, Vol. 14,697-709.

[5] Daloglu, A., 2008. "Pressure Drop in a Channel with Cylinder in Tandem Arrangement", International Comunication in Heat and Mass Tranfer, Vol.35, 76-83.

[6] Lankadasu A. and Vengadesan S., 2007. "Interference Effect of Two Equal-Sized Square Cylinders in Tandem Arrangement: with Planar Shear Flow", International Journal for Numerical Methodes in Fluids. DOI: 10.1002/fld.1670.

[7] Salam, N., Tarakka, R., Jalaluddin, and Bachmid, R., 2017. "The effect of the Addition of Inlet Disturbance Body (IDB) to Flow Resistance Through the Square Cylinders Arranged in Tandem", International Review of Mechanical Engineering (I.RE.M.E.), Vol. 11, No. 3, pp. 181-190.

[8] Hasebe Hiroshi, Watanabe Kenji, Watanabe Yuki and Takashi Nomura Takashi, 2009. "Experimental Study On The Flow Field Between Two Square Cylinders In Tandem Arrangement", The Seventh Asia-Pacific Conference on Wind Engineering (APCWE-VII), Taipei, Taiwan.

[9] Wang Z.J. \& Zhou Y., 2005. "Vortex Interaksion in a Two Side-by-Side Cylinder Near-Wake", International Journal of Heat and Fluid Flow 26, pp. 362-377.

[10] Mingyue Liu, Longfei Xiao and Lijun Yang, 2015. "Experimental investigation of flow characteristics around four square-cylinder arrays at subcritical Reynolds numbers", Int. J. Nav. Archit. Ocean Eng. 7: pp. 906 919.

[11] Ehsan Adeeb, Basharat Ali Haider, Chang Hyun Sohn, 2018. "Flow interference of two sideby-side square cylinders using IB-LBM - Effect of corner radius", Journal Elsevier - Results in Physics 10. pp. $256-263$.

[12] Etminan A., M. Moosavi and N. Ghaedsharafi, 2011. "Characteristics of Aerodynamics Forces Acting on Two Square Cylinders in the Streamwise Direction and its Wake Patterns", Advances in Control, Chemical Engineering, Civil Engineering and Mechanical Engineering ISBN: 978-960474, pp. 209-217.

[13] Cengel Yunus A., and Cimbala John M., 2006. "Fluid Mechanics Fundamentals and Applications", Published by The Mc Graw-Hill Companies, Inc. New York.

[14] Practical Exercises Manual, 2016. "Laminar Flow Visualization and Analysis Unit (LFA)". Buatan Edibon, Spanyol. 